\title{
Stuart Hall, a partir da e na América Latina*
}

\section{Stuart Hall from/in Latin America}

\author{
DANIEL MATO ** \\ Conselho Nacional de Pesquisas Científicas e Técnicas. Ciudad de Buenos Aires, Argentina \\ Universidad Nacional de Tres de Febrero. Ciudad de Buenos Aires, Argentina
}

\section{RESUMO}

Este artigo discute como as ideias de Hall foram incorporadas de forma rápida, rigorosa e crítica pelos estudiosos e intelectuais na América Latina considerados pioneiros no campo dos Estudos Culturais latino-americanos e aqueles que os seguiram; por outros que realizam um trabalho crítico, mas recusam o rótulo de Estudos Culturais; finalmente, por aqueles cujo trabalho poderia ser identificado como estudo cultural, mas que não o consideram como tal. Esta análise leva a concluir que seria simplista limitar a discussão da importância das ideias de Hall na América Latina ao campo dos chamados Estudos Culturais latino-americanos. Esse tema merece um olhar mais aprofundado.

Palavras-chave: Estudos Culturais, genealogias, Stuart Hall, América Latina, prática social

\section{ABSTRACT}

This article discusses how Hall's ideas have been taken up readily, rigorously and critically by scholars and intellectuals in Latin America who can be considered trailblazers in the field of Latin American Cultural Studies and those that followed, as well as others who undertake critical work but refuse the Cultural Studies label, and finally others whose work could readily be identified as Cultural Studies but who have not been taken up as such. This analysis leads to the conclusion that it would be simplistic to constrain the discussion of the significance of Hall's ideas in Latin America to the field of so-called Latin American Cultural Studies; rather this needs to be seen in more complex ways.

Keywords: Cultural Studies, genealogies, Stuart Hall, Latin America, social practice

\footnotetext{
* Artigo publicado on-line no International Journal of Cultural Studies, antes da versão impressa, em 24 de agosto de 2015. Tradução de Dayse Ventura Arosa.

*** Investigador Principal do Conselho Nacional de Pesquisas Científicas e Técnicas (Conicet) no Centro Interdisciplinar de Estudos Avançado na Universidade Nacional de Três de Fevereiro (Untref), Foi professor visitante em universidades da Espanha, Estados Unidos e de vários países da América Latina. E-mail:

dmato2007@gmail.com
} 


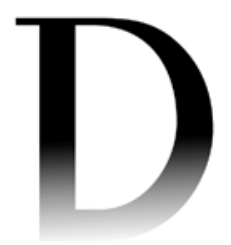

1. Tradução feita a partir da tradução do espanhol para o inglês pelo autor do texto (N.T.).

2. Como forma de diminuir tal desvantagem, ao escrever este artigo, para além da minha coleção pessoal de artigos, conferências e livros sobre o assunto, solicitei e recebi a ajuda de inúmeros colegas por toda a América Latina, que me forneceram ideias, assim como publicações adicionais. Este artigo foi possível graças ao apoio dessas pessoas. No entanto, eu sou o responsável por quaisquer erros que ele contenha. Minha gratidão profunda a esses colegas: Pablo Alabarces, Carlos Altamirano, Vera Candau,

Francisco Carballo, Ana Coiro, Alicia Entel, Ana Carolina Escoteguy, Jose Guilherme Fernandes, Néstor García- Canclini, Rosa Maria HesselSilveira, Jorge Larraín, María Cristina Laverde-

Toscano, Jesús MartínBarbero, Nora Mazziotti, Eduardo Restrepo,

Enrique Rey-Torres, José Luis Saavedra, Carlos Sandoval-García, Liv Sovik, Monica Szurmuk, Mirta Varela, Marisa Vorraber-Costa, Ana Wortman e George Yudice.
ONSIDERANDO QUE ESTE artigo possa atrair leitores em todo o mundo, seria produtivo começar esclarecendo que o termo América Latina se refere a uma região geográfica que compreende mais de 20 países, cada um com uma história social e política específica, sistemas universitários distintos e tradições intelectuais diversas. Além disso, por ser uma área que abrange dois grupos de língua dominante, português no Brasil e espanhol no restante dos países, há uma grande heterogeneidade social e cultural dentro de cada país. Tendo em mente um público leitor no campo dos Estudos Culturais, eu gostaria de chamar a atenção para as palavras de Jesús Martín-Barbero, considerado um dos pioneiros do campo na América Latina, quando aponta que "há uma diferença bastante clara entre os Estudos Culturais da América do Norte, os que surgiram a partir do estudo da literatura na América Latina e aqueles que se moldaram nas ciências sociais" (1997: 52) ${ }^{1}$.

Tal diversidade de histórias e contextos dificulta a tentativa de esboçar, em poucas páginas, um panorama do uso das ideias de Stuart Hall no trabalho de estudiosos e intelectuais na América Latina, a partir dos anos 1980. Isso vem a ser, no mínimo, uma tarefa fragmentada e imperfeita, apesar de intencional, uma vez que até hoje não existe outra análise tão abrangente ${ }^{2}$.

Apesar da diversidade interna à região, elaborar a análise da recepção e uso da obra de Stuart Hall na América Latina como um todo é, de fato, um exercício produtivo, pois a circulação de intelectuais e ideias em toda a região e as redes dela decorrentes têm uma longa história que remonta aos movimentos anticoloniais. Além disso, a relativa facilidade que os falantes de espanhol e português têm em se entender facilita a comunicação e a troca, especialmente dos textos escritos.

\section{O PERÍODO 1960-1990}

Desde os anos 1960, diversos fatores contribuíram, de maneira variada, para o estabelecimento de redes transnacionais de estudiosos e intelectuais, o que facilitou a circulação de ideias entre as fronteiras nacionais. Mesmo antes de o uso da internet se disseminar na América Latina, em 1992, vários fatores sociais fizeram parte do desenvolvimento dessas redes. Entre eles, e particularmente relevante para este artigo, houve o desenvolvimento de dois movimentos político-intelectuais que transcenderam as fronteiras nacionais: o dos intelectuais marxistas que eram críticos da União Soviética, em alguns casos inspirados pelas ideias de Gramsci (Anderson, 1992: 3; Aricó, 1988; Burgos, 2002, 2004); e o movimento criado por teólogos e bispos católicos que surgiu como resultado da Segunda Conferência Geral do Episcopado Latino-Ame- 
ricano, em Medelín, Colômbia, em 1968 (Berryman, 1987). Cada um desses movimentos desenvolveu gradualmente suas próprias redes, e em alguns casos foram parcialmente sobrepostos (Schutte, 1993). Outro fator significativo está relacionado aos regimes ditatoriais em vários países da América Latina, já que um número expressivo de intelectuais viveu no exílio em outros países da região, considerados seguros. Esses países se tornaram o foco da produção de conhecimento, troca de ideias e a posterior construção e/ou fortalecimento das redes que então continuaram a prosperar, à medida que as pessoas retornavam aos seus países de origem. Esse período foi marcado pelo significativo desenvolvimento de projetos intelectuais coletivos, complementado por periódicos e editoras alternativas, produzindo materiais que circulavam por toda a região. Somado a isso, tivemos periódicos acadêmicos e programas de intercâmbio de bolsas e de professores financiados por diversas universidades e governos, assim como o trabalho de algumas organizações não governamentais internacionais e fundações privadas, que desempenharam um papel importante na emergência dessas redes transnacionais.

Da mesma forma, esse período assistiu à criação do Conselho Latino-Americano de Ciências Sociais (CLACSO), em 1967, da Associação Latino-Americana de Investigadores da Comunicação (ALAIC), em 1978, e da Federação Latino-Americana de Faculdades de Comunicação Social (FELAFACS), em 1981. Essas organizações e as redes que elas produziram fomentaram ativamente a circulação de suas ideias através de periódicos e livros impressos ou fotocopiados, artigos fotocopiados, trabalhos de conferência e apresentações, grupos de trabalho (GT), comunicações pessoais e outras formas de troca e colaboração intelectual (León Duarte, 2006). Em 1983, a CLACSO organizou uma conferência sobre Comunicação e Cultura Popular, e em 1986 criou o GT sobre Políticas Culturais, que organizou diversos encontros até 1993.

Essas redes disseminaram obras e ideias de muitos estudiosos latino-americanos e europeus, ainda que, em alguns casos, a indisponibilidade de traduções tenha limitado o material acessível. A obra de Stuart Hall circulou através dessas redes, embora no início de maneira restrita, pois, por muitos anos, ela só estava disponível em inglês. Ainda assim, Encoding and decoding (Hall, 1980) foi lido em inglês, e atraiu um interesse considerável (Ford, 1982; Landi, 1982). Na verdade, muitos autores e analistas que trabalhavam no desenvolvimento de teorias da comunicação na América Latina consideram esse artigo um ponto decisivo na pesquisa em comunicação na região (Bisbal, 2005; Grimson; Varela, 1999; Sunkel, 2004), além de ter estimulado um interesse mais amplo pela obra de Hall, gerando diversas leituras e apropriações críticas 


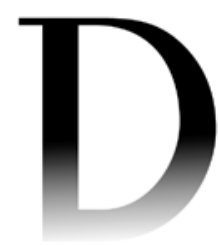

3. Martín-Barbero voltaria a essas observações em 2001, acrescentando referências a dois artigos de Stuart Hall em inglês, incluídos em Hall et al. (1980) Culture, media, language: working papers in cultural studies (1972-1979).

que tanto a ALAIC quanto a FELAFACS fizeram circular através de conferências e publicações.

Um exemplo concreto do uso da obra de Hall pode ser visto no proeminente trabalho do intelectual latino-americano Martín-Barbero. O primeiro texto desse autor que se referiu ao trabalho de Hall foi um artigo publicado na revista da FELAFACS, Diálogos, em 1988, um ano depois da publicação de seu mais famoso livro, De los medios a las mediaciones, 1987. Nesse artigo, Martín-Barbero reconhece as contribuições dos Estudos Culturais para a teoria e a teorização. No entanto, ele faz uma crítica ao que ele identifica como a noção dos Estudos Culturais de conceber a esfera cultural como independente das pressões econômicas. Martín-Barbero mantém essa linha de pensamento em uma nota de rodapé, na qual ele se refere a dois artigos de Stuart Hall e sua publicação em espanhol (1981[1977]; 1984[1980]) ${ }^{3}$. Essa referência mostra como as ideias de Hall não foram adotadas de forma passiva, mas criticamente apropriadas no interior dessas redes latino-americanas. De maneira complementar, em dois artigos associados, um publicado em inglês e o outro em espanhol - novamente em uma revista da FELAFACS -, Martín-Barbero (2002a, 2002b) incorporou algumas elaborações de Stuart Hall sobre as transformações contemporâneas da identidade. Nesse caso, os comentários de Martín-Barbero se baseavam na reimpressão de 1999 da publicação da primeira tradução para o português do livro A questão da identidade cultural (Hall, 1999[1990]).

A diferença de idioma retardou a circulação das ideias de Hall na América Latina. As traduções feitas especificamente para serem utilizadas em grupos de estudo universitários foram, em muitos casos, a primeira forma de compartilhar seus textos. Isso começou a mudar com a publicação da obra de Hall, traduzida tanto para o espanhol (e.g. Hall, 1977 [1969], 1978, 1984a [1980], 1984b [1981], 1984c [1981], 1987 [1984]) quanto para o português (e.g. Hall et al., 1980 [1978]).

\section{OS ANOS 1990}

A partir do início dos anos 1990, as universidades latino-americanas experimentaram, cada vez mais, dois diferentes tipos de pressões que impactaram as práticas acadêmicas, embora com diferentes extensões e graus, conforme os países, universidades e disciplinas. Por um lado, as universidades focavam as demandas de vários movimentos sociais que buscavam transformar a educação superior, para atender melhor às necessidades sociais, lembrando a necessidade de se desenvolverem práticas de alcance social e estabelecer vários 
tipos de programas de ação afirmativa; por outro lado, as universidades estavam sujeitas às pressões das agências estatais e da mídia, no sentido de adotar certas concepções de qualidade acadêmica, usualmente medida de maneira quantitativa, em termos de número de publicações e patentes, número de docentes com $\mathrm{PhD}$ e os indicadores de empregabilidade de seus pós-graduados (Ordorika, 2007). No caso das ciências humanas e sociais, isso levou a privilegiar publicações em detrimento das pesquisas socialmente comprometidas, do ensino e do trabalho social.

Durante esse período, e em certa medida relacionado à última observação, havia um número crescente de estudiosos latino-americanos que procuravam cursos de pós-graduação em universidades dos Estados Unidos e de alguns países da Europa. Alguns dos que procuravam estudos em várias disciplinas das ciências sociais e humanas se interessaram no campo dos Estudos Culturais, que estava cada vez mais visível e, por conseguinte, na obra de Stuart Hall. Além disso, esses fatores contribuíram para a crescente participação de estudiosos latino-americanos em conferências organizadas por associações baseadas nos Estados Unidos, como a Associação de Estudos Latino-Americanos e a Associação de Línguas Modernas, nas quais as ideias de Stuart Hall foram incorporadas antes e mais amplamente dentro de contextos específicos da América Latina.

Ademais, com a expansão do uso acadêmico da internet na América Latina, as redes acadêmicas cresceram e se tornaram diversificadas à medida que a circulação de ideias transnacionais e os intercâmbios associados se multiplicavam. Como resultado, a disseminação e o interesse na obra de Stuart Hall também cresceram, pois ela foi facilitada pela disponibilidade de novas traduções de seu trabalho para o espanhol (1993a, 1993b[1989], 1994a [1973], 1994b [1980], 1998 [1985], 1999 [1990]) e para o português (1996[1990], 1997a, 1997b).

Como exemplo concreto da referência e do uso da obra de Hall por estudiosos latino-americanos, podemos citar o trabalho de Néstor García-Canclini. Considerado um dos pioneiros dos Estudos Culturais na América Latina junto a Jesús Martín-Barbero, sua primeira referência sobre a obra de Stuart Hall apareceu num artigo do início dos anos 1990 (García-Canclini, 1991: 18-, 22), referindo-se à Culture, media, language (1980), uma coleção de ensaios que García-Canclini abordaria com maior profundidade em um artigo conceitual publicado dois anos mais tarde (1993: 37-38). Em 1995, na edição original em espanhol de seu conhecido Consumers and citizens [Consumidores y ciudadanos (1995: 113)], García-Canclini incluiu outra referência ao trabalho de Hall, dessa vez em um artigo de sua autoria (1991). Entretanto, ele não fez 


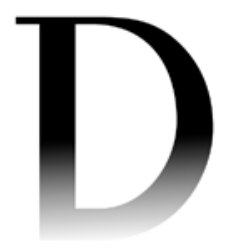

4. Referências aos trabalhos de Williams e Hoggart foram incluídas no primeiro livro de García-Canclini (1982).

Referências a textos de Williams e de E. P. Thompson foram incluídas em MartínBrabero (1987). No entanto, nos dois casos eram apenas algumas referências entre mais de 100 autores.

5. Beatriz Sarlo afirmou enfaticamente: "Na Argentina, não os chamamos de Estudos Culturais". Para ela, esse termo foi colocado em circulação de massa pela academia americana. Ao invés disso, ela prefere falar em termos de análise cultural (1997, p. 90). Jesús Martín-Barbero observou que "Fazíamos Estudos Culturais bem antes que esse rótulo aparecesse" (1997, p. 52).

De forma semelhante,

Néstor García-Canclini apontou que "Tornei-me envolvido nos Estudos Culturais antes de tomar consciência de que se chamavam assim" (1996, p. 84). Discuti essas questões profundamente em um artigo anterior, defendendo a necessidade de compreender que o uso do rótulo Estudos Culturais Latino-

Americanos é, por vezes, rejeitado, porque é interpretado como algo que ignora a história intelectual dessa parte do mundo, e também porque isso implica um sistema que exclui um campo mais amplo de práticas intelectuais que tem suas raízes e história na América Latina (2003). mais nenhuma referência ao trabalho de Hall em seus livros posteriores, salvo em La globalización imaginada (1999) [A globalização imaginada (2003)].

Os dois primeiros e mais aclamados livros de García-Canclini (1982, 1989), assim como o primeiro e consagrado livro de Martín-Barbero (1987), não fazem referência à obra de Hall, o que nos ajuda a compreender por que eles afirmam que fazem Estudos Culturais bem antes de essa denominação ser estabelecida $^{4}$. Da mesma maneira, Beatriz Sarlo, também considerada uma das pioneiras dos Estudos Culturais na América Latina, opõe-se ao rótulo de Estudos Culturais para o seu trabalho (1997). Todavia, ela destaca a importância da obra de Hall, em especial suas palavras a respeito das ideias de Raymond Williams sobre cultura e política, como uma referência-chave no formato da revista Punto de vista, um influente projeto político-cultural desenvolvido por ela e Carlos Altamirano durante o período da última ditadura na Argentina (2000: 312).

As objeções ao rótulo de Estudos Culturais ${ }^{5}$ e as observações críticas de Martín-Barbero mencionadas anteriormente são importantes para entender como as ideias de Hall foram prontamente retomadas, rigorosa e criticamente, não apenas por aqueles que são em geral vistos como pioneiros nos Estudos Culturais da América Latina, mas também por outros estudiosos e intelectuais cujos trabalhos são pouco associados a tal pioneirismo (ver Ford, 1982; 1994; Landi, 1982) e pelos que trabalham a partir de perspectivas convergentes e cujo trabalho não foi consagrado como Estudos Culturais (ver Alabarces et al., 2008; Diviani, 2014; Mato, 2003).

É interessante observar que uma pequena conferência ocorrida na Escócia, em outubro de 1996, parece ter desempenhado um papel relevante no crescimento da apreciação da obra de Stuart Hall por alguns estudiosos latino-americanos bastante conhecidos. A conferência Fronteiras culturais: identidade e comunicação na América Latina, organizada pelo Media Research Institute da Universidade de Stirling (Escócia), em cooperação com 21 estudiosos da Associação Mundial para a Comunicação Cristã, teve lugar na universidade e contou com a participação de 21 estudiosos de Estudos Culturais e de Comunicação da América Latina, EUA, Índia e vários países da Europa. Essa foi a primeira vez que Stuart Hall, Néstor García-Canclini e Jesús Martín Barbero se encontraram pessoalmente - e foi um encontro bastante frutífero, de acordo com o que García-Canclini e Martín-Barbero me disseram em comunicações pessoais. Após o encontro, García-Canclini (1997: 23) fez referência a um artigo de Hall (1991) numa publicação resultante da conferência, em que fazia uma análise sobre hegemonia e diferença no contexto das relações entre Estados Unidos e América Latina. Há referências sobre perguntas que 
Hall fez a ele durante o encontro, evidenciadas em algumas reflexões sobre o tema apresentado em seu livro La globalización imaginada (1999: 122). Martín-Barbero, por outro lado, apontou várias vezes que, durante esse encontro, Hall destacou a necessidade de os estudiosos masculinos da América Latina incorporarem a perspectiva de gênero em seus trabalhos (2014: 7) ${ }^{6}$.

\section{DOS ANOS 2000 EM DIANTE}

Em 1999, a CLACSO criou seu GT sobre transformações culturais e sociais e, em 2001, mudou seu nome para Cultura e Poder. Logo depois, seria criado um GT sobre consumo cultural e muitos outros sobre temas similares. Desde 2004, os membros desses GT ofereceram uma série de seminários de pós-graduação através do campus virtual da CLACSO. Como fui o fundador da cadeira e mais tarde um membro regular de um desses GT por muitos anos, assim como professor de dois desses seminários na internet, posso - como participante - destacar que algumas ideias de Stuart Hall foram discutidas em reuniões de GT e em alguns dos seminários da internet, mesmo quando não havia uma frequente remissão a seu trabalho nos livros que deles resultaram. Atribuo isso ao fato de as ideias de Stuart Hall terem feito parte de sistemas maiores de metarreferências desses GT e seminários, bem como daqueles de um bom número de autores da América Latina, Europa e Estados Unidos. Contudo, como discutirei mais adiante neste artigo, um interesse mais focado na obra de Stuart Hall logo se tornaria mais evidente dentro das redes da CLACSO.

O interesse pelas ideias de Stuart Hall cresceu continuamente nesse período em vários lugares da América Latina. Um fator interessante que evidencia essa tendência, além de ter sido o meio para ela acontecer, é o crescente número de traduções de ensaios de Hall para o espanhol, publicados a partir de 2000 (Hall, 2000, 2003, 2004, 2005 [1986], 2008a [1992], 2008b, 2010 [2010], 2014; Hall; du Gay, 2003 [1986]; Hall; Mellino, 2011 [2007]). Além disso, como será discutido a seguir, houve três livros publicados em anos anteriores, que incluíam coleções de seus artigos, um em português e dois em espanhol.

Duas conferências internacionais que ocorreram em 2000 também desempenharam um importante papel, no sentido de colocar as ideias de Stuart Hall ao alcance dos estudiosos latino-americanos. Uma delas foi a $3^{\text {a }}$ Conferência Internacional Crossroads in Cultural Studies, ocorrida em Birmingham (GB), em junho, assistida por vários estudiosos latino-americanos, e Hall foi um de seus oradores principais. Além do mais, em julho de 2000, Stuart Hall visitou o Brasil como convidado para fazer uma palestra de abertura da VII Conferência da
6. Em várias ocasiões,

Martín-Barbero se referiu a essa demanda de Stuart Hall, isto é, uma comunicação pessoal, assim como uma entrevista dada um mês antes da conferência em Stirling e publicada no ano seguinte (1997: 52-53). 
Associação Brasileira de Literatura Comparada (ABRALIC), ocorrida na Bahia. O convite foi uma iniciativa consciente da diretoria da ABRALIC para chamar a atenção para o renomado intelectual negro internacional, em uma cidade de cultura negra marcada pela opressão racista (Sovik, 2014a: 11). A presença e a palestra de Hall na conferência inspiraram o público, e levaram à publicação do primeiro livro com traduções para o português, de uma coleção de 12 artigos de Hall e duas entrevistas (Sovik, 2003b). O livro coincidiu com um momento significativamente importante no Brasil, porque surgiu em uma conjuntura específica de debates públicos sobre racismo e política de cotas para estudantes negros, e de políticas federais relativas à educação superior, referentes ao lugar social e institucional do trabalho intelectual. Hall tinha muito a dizer sobre ambas as questões, o que manteve esse tema em destaque na escolha dos artigos incluídos no volume, a fim de abordar essa conjuntura política, cultural e acadêmica particular (Sovik, 2003a: 21). Esse livro foi o primeiro do gênero na América Latina, e rapidamente tornou-se um best-seller acadêmico. Em termos de política de idioma e público, esse texto teve uma influência especial no crescimento do público da obra de Hall, pois tornou seus ensaios acessíveis não apenas aos brasileiros, mas a muitos falantes de espanhol latino-americanos que conseguiam ler em português, mas não em inglês.

As ideias de Stuart Hall, no entanto, circulavam no Brasil antes disso, particularmente nos campos da comunicação e educação, tanto através das traduções em português (1996 [1990], 1997a, 1997b), como da leitura de seus livros em inglês ou espanhol. A publicação do livro mencionado e sua receptividade estão inscritas em uma história rica e diversa da academia e outras práticas intelectuais e movimentos culturais, políticos e sociais. As ideias de Stuart Hall contribuíram para discussões de experiências nos campos de estudo sobre as comunicações, a memória social e os museus (e.g., Coiro Moraes, 2014; Escobar; Coiro Moraes, 2013; Escosteguy, 2013). A articulação entre educação e Estudos Culturais iniciada no começo dos anos 1990, na Faculdade de Educação da Universidade Federal do Rio Grande do Sul tem relevância especial. Essa conexão ganhou lugar institucional pela primeira vez em 1996 e continua até hoje, gradualmente envolvendo outras universidades em inúmeros estados brasileiros. Desde a sua fundação, essa experiência envolveu a leitura de vários textos de Stuart Hall, particularmente aqueles originalmente preparados para a Universidade Aberta, onde eram lidos inicialmente através de traduções de circulação limitada, impressa ou fotocopiada, a fim de serem utilizados nas aulas e em grupos de estudo. Isso levou, por sua vez, à publicação de dois artigos de Stuart Hall (1997a, 1997b) traduzidos para português (Vorraber-Costa et al., 2014; Wortmann et al., 2015). 
Há também convergências significativas entre as propostas de intervenção intelectual de Stuart Hall e certas experiências de teatro e música na América Latina. Um exemplo a destacar é a forte prática político-cultural desenvolvida por Augusto Boal, que começou nos anos 1960 e continuou até sua morte, em 2009. Em momentos diferentes, ela foi conceituada como Teatro Popular ou Teatro do Oprimido (Boal, 1975, 1980a, 1980b; Sant'anna, 2002). Outras práticas político-culturais importantes, que foram interpretadas como convergentes com as propostas político-culturais de Hall, foram as desenvolvidas pelo Bloco Olodum, a partir de 1979, e o AfroReggae, desde 1993 (Sant'anna, 2002; Sovik, 2014b). O viés acadêmico da maioria das publicações de Estudos Culturais, que tendiam a privilegiar o material escrito em detrimento de outras práticas discursivas, parece ter impedido uma maior atenção a esses tipos de práticas intelectuais, em geral desenvolvidas fora ou além dos campi universitários. Todavia, alguns autores usaram explicitamente as ideias de Hall para discutir algumas dessas experiências (ver Carvalho, 2009; Mato, 2003; Sovik, 2014b). Um caso em questão é o estudo documentado que Aline Carvalho (2009) conduziu sobre o programa Pontos de Cultura do Ministério da Cultura do Brasil, no qual ela destaca a importância das ideias de Stuart Hall, assim como as de García-Canclini, Martín Barbero e outros, para discutir a experiência do programa. A propósito, Augusto Boal esteve envolvido nesse programa político-cultural, o que fornece pistas adicionais às convergências significativas entre a prática dele e as ideias de Hall sobre cultura e poder, assim como seu próprio caminho de fazer Estudos Culturais (Mato, 2014). Tais convergências podem ser identificadas na tradução dos livros de Boal para o espanhol (1975, 1980a, 1980b), publicados em uma coleção de livros coordenada por Néstor García-Canclini.

Em 2009, a CLACSO criou sua própria rede latino-americana de programas de pós-graduação em políticas e Estudos Culturais, que conta com a participação de seis programas conhecidos em países de América Latina. Em 2010, essa rede publicou seu primeiro livro coletivo, En torno a los estudios culturales: localidades, trayectorias y disputas, editado por Nelly Richard (2010), catedrático de um dos programas. O volume trouxe várias respostas de um questionário sobre Estudos Culturais, previamente aprovado, dadas pelos catedráticos do programa e sua comissão diretora, em um dos casos, assim como as de um colega convidado que também dirigia um programa de pósgraduação relacionado. Artigos de Néstor García-Canclini e Jesús Martín-Barbero também estão incluídos, assim como uma longa - quase 40 páginas - e valiosa seção intitulada Debate contínuo, que apresenta trocas recentes entre alguns catedráticos do programa (Alejandro Grimson, Mareia Quintero Ri- 
vera, Gonzalo Portocarrero, Eduardo Restrepo, Nelly Richard e Víctor Vich). Enquanto lia as respostas ao questionário, percebi como, na maioria dos casos, as contribuições de Stuart Hall foram destacadas e supervalorizadas. Além disso, eram ideias associadas às de cultura e poder, a práticas intelectuais e intervenção, e a palavras-chave como hegemonia, gênero, raça e colonialismo. A seção intitulada Debate contínuo também contém muitas referências a Stuart Hall. As observações de Alejandro Grimson nessa seção são particularmente diretas nesse artigo. Ele afirma: "Bom, algo que ocorreu a mim enquanto lia os textos preparados para este encontro é que ninguém se sente muito confortável com os Estudos Culturais [enquanto um conceito] [...] Mas certamente temos referências em comum, como Stuart Hall" (Richard, 2010: 147).

Outro componente significativo dessa história é a edição do livro Sin garantías: trayectorias y problemáticas en estudios culturales (Restrepo et al., 2010), por Eduardo Restrepo, Victor Vich e Catherine Walsh. Os dois primeiros são catedráticos de dois programas na Rede CLACSO de programas de pós-graduação, e Walsh preside outro programa que não faz parte da rede, mas foi especialmente convidada para responder ao questionário e, portanto, fazer parte do livro dele resultante. O livro inclui 26 dos artigos de Hall traduzidos para o espanhol, junto com a introdução feita pelos três editores, na qual defendem a leitura de Stuart Hall na América Latina. Embora não seja possível analisar aqui cada um dos cinco argumentos delineados, eles apontam, em geral, a crítica de Hall sobre o eurocentrismo, a importância analítica das categorias de raça e etnia com base em Gramsci, a discussão sobre a relação entre multiculturalismo, comunidade e estado-nação, a vocação política dos Estudos Culturais e, parafraseando Lawrence Grossberg - o trabalho de Hall poderia ser entendido como "política teorizante e teoria politizante". O livro teve uma receptividade bastante positiva, e certamente irá facilitar a divulgação e o aprofundamento da leitura da obra de Hall na América Latina.

Outra coleção de obras de Stuart Hall foi publicada recentemente no livro Discurso y poder en Stuart Hall (Soto Sulca, 2013). Esse volume traz a tradução de seis ensaios de Hall, assim como dois artigos sobre sua obra, e uma apresentação de quase 40 páginas escrita por Eduardo Restrepo (2013), que traz algumas referências relativas à vida de Stuart Hall e ao estilo de sua obra intelectual, com ênfase em seu contextualismo radical. Aqui, mais uma vez, encontramos a expressão de Grossberg de "políticas de teorização e teoria da politização" para caracterizar a obra de Hall.

Em agosto de 2014, foi publicado o livro Stuart Hall desde el sur: legados y apropiaciones (Restrepo, 2014), resultado do seminário de pós-graduação Stuart Hall e os Estudos Culturais na América Latina e Caribe, que Eduardo 
Restrepo promoveu em 2013, no Campus Virtual da CLACSO. Contém 11 ensaios escritos pelos alunos do seminário, de cinco países da América Latina, além de um capítulo escrito por Restrepo. Cinco artigos abordam questões conceituais, enquanto os demais enfatizam questões associadas a identidades étnicas e relações interculturais.

\section{CONCLUSÕES}

O panorama oferecido nas páginas deste artigo mostra como as ideias de Hall foram retomadas pronta, rigorosa e criticamente pelos estudiosos e intelectuais latino-americanos considerados pioneiros no campo dos Estudos Culturais da América Latina e aqueles que os seguiram; outros que aceitaram o trabalho crítico, mas rejeitaram o rótulo de Estudos Culturais; e os que produziram trabalhos que podem ser diretamente identificados como Estudos Culturais, mas que não os assumiram como tais. Esta análise leva à conclusão de que poderia ser simplista limitar a discussão sobre o significado das ideias de Hall na América Latina, restringindo-o ao campo dos Estudos Culturais Latino-Americanos; é necessário um olhar mais aprofundado.

Além disso, os exemplos discutidos neste panorama, assim como algumas publicações anteriores, reconheceram as convergências e/ou articulações entre o estilo de trabalho intelectual de Stuart Hall e suas bases político-epistemológicas e o trabalho de alguns intelectuais proeminentes latino-americanos. Existem estudos, por exemplo, no trabalho de Orlando Fals-Borda ${ }^{7}$, com experiências específicas de pesquisa de ação participativa com movimentos sociais (ver Lenz, 2012; Valencia, 2011), e também na obra de Paulo Freire ${ }^{8}$ (Hernández; Vigotsky, 2004), que manifestam um desejo pela práxis, procurando trabalhar fora da academia ou, em alguns casos, dentro e fora dela (Mato, 2000, 2003).

Isso me remete a uma observação de Stuart Hall em junho de 2000, quando pedi a ele que escrevesse um ensaio sobre Estudos Culturais e a importância da prática. Ele me deu uma resposta surpreendente que me marca até hoje, porque a achei pessoalmente iluminante e inspiradora: "Veja, Daniel, não escrevo mais sobre Estudos Culturais, dedico-me a fazer Estudos Culturais". Na verdade, o que ele estava fazendo naquela época era participar de um debate público sobre raça e racismo na Grã-Bretanha. Esse jeito de fazer estava relacionado à sua participação na Comissão de Runnymede Trust Sobre o Futuro Multiétnico da Grã-Bretanha. Como já discuti longamente em outro artigo, a Comissão publicou suas descobertas e recomendações em um relatório revisto e incorporado pelo Fórum sobre Relações Interraciais do Ministério do In-
7. Alguns textos em inglês que discutem o trabalho do antropólogo colombiano Orlando Fals-Borda são: Mato (2000) e Fals-Borda; Rahman (1991).

8. Sobre Freire em inglês, ver Giroux (2000) e Mato (2000). A propósito, vale a pena mencionar que Jesús Martín-Barbero (2010, p. 136-137) reforçou o significado das contribuições de Paulo Freire para o campo atualmente chamado de Estudos Culturais LatinoAmericanos. 
terior e pelo Encontro do Grupo Parlamentar sobre Raça e Comunidade, por algumas organizações de autoridades locais e vários conselhos sobre igualdade racial. Além do mais, o relatório foi objeto de uma série de palestras, seminários e simpósios na educação superior (Mato, 2014), e suas recomendações também informaram eventos de formação em escolas.

É importante observar que a contribuição teórica de Hall, seu estilo de prática intelectual e suas reflexões e argumentos relativos ao trabalho intelectual e acadêmico foram rapidamente incorporados, de forma rigorosa e crítica na América Latina, não apenas como referências acadêmicas, mas também como fontes que informam ativamente projetos sociopolíticos engajados. As conjunturas particulares das experiências na Argentina e no Brasil discutidas anteriormente destacam-se nesse olhar (Sarlo, 2000; Sovik, 2003a, 2014a, 2014b), ainda que não sejam as únicas. Existe uma ampla discussão que ilustra esse tipo de experiência na apresentação de textos de vários volumes publicados na América Latina, reunindo artigos de Hall (Restrepo et al., 2010; Soto Sulca, 2013; Sovik, 2003b), assim como nos ensaios incluídos no volume recentemente editado sobre sua obra (Restrepo, 2014). M

\section{REFERÊNCIAS}

ALABARCES, P.; AÑÓN, V.; CONDE, M. Un destino sudamericano. La invención de los estudios sobre cultura popular en la Argentina. In: ALABARCES, P.; RODRÍGUEZ, M. G. (eds.). Resistencias y mediaciones. Estudios sobre cultura popular. Buenos Aires: Paidós, 2008. p. 261-280.

ANDERSON, P. English questions. London: Verso, 1992.

ARICÓ, J. La cola del diablo. Buenos Aires: Puntosur, 1988.

BERRYMAN, P. Liberation Theology: The essential facts about the revolutionary movement in Latin America and beyond. New York: Pantheon, 1987.

BISBAL, M. Recepción y TV en Venezuela: itinerario de una línea investigativa. Comunicación: estudios venezolanos de comunicación, n. 131, p. 28-37, 2005.

BOAL, A. Técnicas latinoamericanas de teatro popular. México: Nueva Imagen, 1975.

. Teatro del oprimido 1: teoria y practica. México: Nueva Imagen, 1980a.

. Teatro del oprimido 2: ejercicios para actores y no actores. México: Nueva Imagen, 1980b.

BURGOS, R. The Gramscian intervention in the theoretical and political production of the Latin American left. Latin American Perspectives, v. 29, n. 1, p. 9-37, 2002. DOI: http://dx.doi.org/10.1177/0094582X0202900102 
Los gramscianos argentinos. Cultura y política en la experiencia de pasado y presente. México: Siglo XXI, 2004.

CARVAlHO, A. Produção de cultura no Brasil: da tropicália aos pontos de cultura. 2. ed. Rio de Janeiro: Luminária Academia, 2009.

COIRO MORAES, A. L. Estudos culturais aplicados a pesquisas em comunicação. In: SOUZA, R. M. V.; MELO, J. M.; MORAIS, O. J. (eds.). Teorias da comunicação: correntes de pensamento e metodologia de ensino. São Paulo: Intercom, 2014. p. 226-259.

DIVIANI, R. J. Jaime Rest y Aníbal Ford en los años sesenta y setenta ¿Una anticipación argentina de los estudios culturales de birmingham? Question, n. 42, p. 57-68, 2014.

ESCOBAR, G. V.; COIRO MORAES, A. L. Rodas de lembranças do Museu Comunitário Treze de Maio: comunicação, educação e identidade de mulheres negras. In: MATTOS, J. R. (Ed.). Museus e africanidades. Porto Alegre: Edições Museu Júlio de Castilhos, 2013. p. 157-182.

ESCOSTEGUY, A. C. Stuart Hall: esboço de um itinerário biointelectual. Revista FAMECOS, n. 21, p. 61-74, 2013.

FALS-BORDA, O.; RAHMAN, A. Action and knowledge: breaking the monopoly with participatory action research. New York: Appex Press, 1991.

FORD, A. La utopía de la manipulación. Contraseña, v. 1, n. 2, p. 56-57, 1982. . Navegaciones: comunicación, cultura y crisis. Buenos Aires: Amorrortu, 1994.

GARCÍA-CANCLINI, N. Las culturas populares en el capitalismo. México: Ed. Nueva Imagen, 1982.

. Culturas híbridas: estrategias para entrar y salir de la modernidad. México: Ed. Grijalbo, 1989.

. Los estudios culturales de los 80 a los 90: perspectivas antropológicas y sociológicas en América Latina. Iztapalapa, v. 11, n. 24, p. 11-26, 1991. . El consumo cultural y su estudio en México: una propuesta teórica. In: GARCÍA-CANCLINI N. (ed.). El consumo cultural en México. Mexico City: México Consejo Nacional para la Cultura y las Artes, 1993. p. 15-42. . Consumidores y ciudadanos: conflictos multiculturales de la globalización. México: Ed. Grijalbo, 1995.

. Cultural studies questionnaire. Journal of Latin American Cultural Studies, v. 5, n. 1, p. 83-87, 1996.

. Hybrid cultures and communicative strategies. Media Development, v. 44, n. 1, p. 22-29, 1997.

. La globalización imaginada. Buenos Aires: Paidós, 1999.

A globalização imaginada. São Paulo: Iluminuras, 2003. 
GIROUX, H. Stealing innocence: youth, corporate power, and the politics of culture. New York: St. Martin's Press, 2000.

GRIMSON, A.; VARELA, M. Audiencias, cultura y poder: estudios sobre televisión. Buenos Aires: EUDEBA, 1999.

HALL, S. Los hippies: una contracultura. Barcelona: Anagrama, 1977. (Tradução da publicação The Hippies: an American Moment, 1969.)

. Pluralismo, raza y clase en la sociedad Caribe. In: REX, J. (ed.) Raza

$y$ clase en la sociedad postcolonial. Un estudio de las relaciones entre los grupos étnicos en el Caribe de lengua Inglesa, Bolivia, Chile y México. Madrid: UNESCO, 1978, p. 149-181. (tradução da publicação: Pluralism, race and class in Caribbean society, in Race and class in post-colonial society, Paris, 1978.)

. La cultura, los medios de comunicación y el "efecto ideológico". In: CURRAN, J.; GUREVITCH, M.; WOOLLACOTT, J. (eds.). Sociedad y comunicación de masas. Mexico: Fondo de Cultura Económica, 1981. p. 357-393. (tradução da publicação: Culture, the media and the ideological effect. In: CURRAN, J.; GUREVITCH, M.; WOOLLACOTT, J. (eds.). Mass communication and society. London: Edward Arnold, 1977. p. 315348.)

. Estudios culturales: dos paradigmas. Hueso Húmero, n. 19, p. 69-77, 1984a. (Publicado originalmente em Media, Culture \& Society, n. 2, p. 57-72, 1980.)

Notas sobre la desconstrucción de lo popular. In: SAMUEL, R. (ed.). Historia popular y teoría socialista. Barcelona: Crítica, p. 93-110, 1984b. (Tradução da publicação: Notes on deconstructing 'the popular', 1981.)

. En defensa de la teoría. In: SAMUEL, R. (ed.) Historia popular y teoría socialista. Barcelona: Crítica, p. 277-286, 1984c. (Tradução da publicação: In defence of theory, 1981.)

. La educación en crisis. Revista de educación, n. 283, p. 29-35, 1987. (Tradução da publicação: Education in crisis, 1984.)

. The local and the global: globalization and new ethnicities. In: KING, A. (ed.). Culture, globalization, and the world-system. Binghamton: University of New York at Binghamton, 1991.

. La hegemonía audiovisual. In: DELFINO, S. (ed.) La mirada oblicua: estudios culturales y democracia. Buenos Aires: La Marca, 1993a.

Nuevos tiempos. In: DELFINO, S. (ed.) La mirada oblicua: estudios culturales y democracia. Buenos Aires: La Marca, 1993b. (Tradução da publicação: New times, 1989.) 
Codificar/decodificar. In: ENTEL, A (ed.) Teorías de la comunicación: cuadros de época y pasiones de sujetos. Buenos Aires: Editorial Docencia, 1994a. (Tradução da publicação: Encoding/decoding. In: HALL, S.; HOBSON, D.; LOWE, A.; TILLIS, P. (eds). Culture, media, language: working papers in cultural studies, 1972-79. London: Hutchinson, 1980; extrato editado do livro de HALL, S. Encoding and decoding in the television discourse. CCCS stencilled paper n. 7, Birmingham: CCCS, 1973.)

. Estudios culturales: dos paradigmas. Causas y azares, Buenos Aires, n. 1, n.p., 1994b. (Tradução da publicação: Cultural studies: two paradigms, 1980.). DOI: http://dx.doi.org/10.1177/016344378000200106 . Identidade cultural e diáspora. Patrimonio cultura e artistico nacional, Rio de Janeiro, n. 24, n.p., 1996. (Tradução da publicação: Cultural identity and diaspora, 1990.)

. A centralidade da cultura. Educação e realidade, v. 22, n. 2, 1997a. A identidade cultural na pós-modernidade. Rio de Janeiro: DP\&A, 1997b. (Tradução da publicação: The question of cultural identity. In: HALL, S., HELD, D.; MCGREW, T. (eds.). Modernity and its futures. Cambidge: Polity Press/Open University Press, 1992. p. 274-316.)

Significación, representación, ideología: Althusser y los debates post-estructuralistas. In: CURRAN J.; MORLEY, D.; WALKERDINE, V. (eds.). Estudios culturales y comunicación: análisis, producción y consumo cultural de las políticas de identidad y el posmodernismo. Barcelona: Paidós, 1998. p. 27-61. (Tradução da publicação: Signification, representation, ideology: Althusser and the post-structuralist debates, 1985.)

Identidad cultural y diáspora. In: GÓMEZ, S. C.; RIVERA, O. Guardiola; Benevides, C. M. (eds.). Pensar (en) los intersticios. Bogotá: Pontificia Universidad Javeriana, 1999. p. 131-145. (tradução da publicação Cultural identity and diaspora, 1990.)

El gran espectáculo hacia ninguna parte. In: JACQUES, M. (ed.). ¿Tercera vía o neoliberalismo? Barcelona: Icaria Editorial, 2000, p. 61-84. . Pensando en la diáspora: en casa, desde el extranjero. In: JÁUREGUI, C.; DABOVE, J. P. (eds.). Heterotopias: narrativas e la identidad y la alteridad en Latinoamérica. Pittsburgh, PA: Instituto Internacional de Literatura Iberoamericana, 2003.

. Codificación y decodificación en el discurso televisivo. Cuadernos de información y comunicación, Madrid, n. 9, n.p., 2004.

. La importancia de Gramsci para el estudio de la raza y la etnicidad. Revista colombiana de antropología, Bogotá, v. 41, p. 219-257, Jan./Dez. 
2005. (Tradução da publicação: Gramsci's relevance for the study of race and ethnicity, 1986.)

- ¿Qué es lo "negro" en la cultura popular negra? In: CUNIN, E. (ed.) Textos en diáspora. Una antología sobre afrodescendientes en América. Cidade do México: Instituto Nacional de Antropología e Historia, Centro de estudios mexicanos y centroamericanos, Instituto Francés de estudios andinos, 2008a. p. 207-226. (Tradução da publicação: What is this 'black' in black popular cuture?, 1992.)

- ¿Cuándo fue lo postcolonial? In: MEZZADRA, S. et al., Estudios postcoloniales: ensayos fundamentales. Madrid: Traficantes de Sueños, $2008 \mathrm{~b}$.

Vida y momentos de la primera Nueva Izquierda. New left review, n. 61, p. 163-182, 2010. (Tradução da publicação: Life and times of the first New Left, 2010.)

. Rituales de resistencia. Madrid: Traficantes de Sueños, 2014.

HALL, S; GAY, P. Cuestiones de identidad cultural. Buenos Aires: Amorrortu, 2003. (Tradução da publicação: questions of cultural identity, 1996.)

HALL, S.; MELLINO, M. La cultura y el poder: conversaciones sobre los cultural studies. Buenos Aires. Amorrortu, 2011. (Tradução da publicação: $L a$ cultura e il potere: conversazione sui cultural studies, 2007.)

HALL, S. et al. (eds.). Culture, media, language. London: Hutchinson, 1980.

HALL, S.; LUMLEY, B; MCLENNAN, G. Política e ideologia: Gramsci. In: HALL, S. et al. Da ideologia. Rio de Janeiro: Jorge Zahar, 1980. (Tradução da publicação: On ideology, centre for contemporary cultural studies, 1978.)

HERNÁNDEZ, G.; VISOTSKY, J. Aprendizaje y enseñanza de la historia. Participación e historia en educación de adultos. Quinto Sol, n. 8, p. 91-123, 2004.

LANDI, O. Comunicación, cultura y proceso político. Crítica y utopía, n. 7, 1982. Disponível em: <bibliotecavirtual.clacso.org.ar/ar/libros/critica/ nro7/landi.pdf $>$. Acesso em: 20 ago. 2014.

LENZ, S. Investigación participativa en Argentina: tres experiencias del campo educativo en el contexto de la restitución de la democracia. Forum qualitative sozialforschung/forum: qualitative social research, v. 13, n. 1, 2012. Disponível em: <http://nbn-resolv- ing.de/urn:nbn:de:0114-fqs120133>. Acesso em: 20 ago. 2014.

LEÓN DUARTE, G. A. Sobre la institucionalización del campo académico de la comunicación en América Latina. Una aproximación a las características estructurales de la investigación Latinoamericana en comunicación. Tese (doutorado) - Univ. Autónoma de Barcelona, 2006. 
MARTÍN-BARBERO, J. De los medios a las mediaciones: comunicación, cultura y hegemonía. Barcelona: Gustavo Gili, 1987.

. Euforia tecnológica y malestar en la teoría. Diálogos de la comunicación, n. 20, 1988.

. Nosotros habíamos hecho estudios culturales mucho antes que esta etiqueta apareciera. Entrevista a Jesús Martín-Barbero. Dissens, n. 3, p. 47-53, 1997.

Al sur de la modernidad: comunicación, globalización y multiculturalidad. Pittsburgh: Instituto Internacional de Literatura Iberoamericana, Universidad de Pittsburgh, 2001.

- Tecnicidades, identidades, alteridades: desubicaciones y opacidades de la comunicación en el nuevo siglo. Diálogos, p. 8-25, 2002a.

Identities: traditions and new communities. Media, culture \& society, v. 24, n. 5, p. 621-641, 2002b. DOI: 10.1177/016344370202400504

. Notas para hacer memoria de la investigación cultural en Latinoamérica. In: RICHARD, N. (ed.). En torno a los Estudios Culturales: localidades, trayectorias y disputas. Santiago de Chile: CLACSO; Editorial ARCIS, 2010. p. 133-142.

. Mensaje del Dr. Jesús Martín-Barbero en la ceremonia solemne en que la Universidad de Guadalajara le entrega del título de Doctor Honoris Causa. Paraninfo Enrique Díaz de León. Guadalajara: Universidad de Guadalajara, 12 jun. 2014. Disponível em: <http://www.udg.mx/sites/default/ files/2014_06_12_mensaje_de_jesus_martin_barbero.pdf $>$. Acesso em: 2 dez. 2015.

MATO, D. Not "studying the subaltern", but studying with "subaltern" social groups, or, at least, studying the hegemonic articulations of power. $\mathrm{Ne}$ pantla: views from the south, v. 1, n. 3, p. 479-502, 2000.

. Latin American intellectual practices in culture and power: experiences and debates. Cultural studies, v. 17, n. 6, p. 783-804, 2003. DOI: 10.1080/0950238032000150020

. Stuart Hall on 'doing cultural studies'. Inter-Asia journal of cultural studies, v. 15, n. 2, p. 202-204, 2014. DOI: 10.1080/14649373.2014.917862

ORDORIKA, I. Universidades y globalización: tendencias hegemónicas y construcción de alternativas. Revista educación superior y sociedad, v. 12, n. 1, p. 175-190, 2007.

RESTREPO, E. Presentación. In: SULCA, R. S. (ed.) Discurso y poder en Stuart Hall. Huancayo, Perú: Imprenta Grafica MELGRAPHIC EIRL, 2013. p. 9-48. . (ed.). Stuart Hall desde el sur: legados y apropiaciones. Buenos Aires: CLACSO, 2014. 
RESTREPO, E.; WALSH C.; VICH, V (eds.). Sin garantías: trayectorias y problemáticas en estudios culturales. Popayán; Lima; Bogotá: Instituto de Estudios Sociales y Culturales Pensar; Instituto de Estudios Peruanos; Universidad Andina Simón Bolívar, 2010.

RICHARD, N. (ed.). En torno a los estudios culturales: localidades, trayectorias y disputas. Santiago de Chile: CLACSO; Editorial ARCIS, 2010.

SANT'ANNA, C. Poder e cultura: as lutas de resistência crítica através de duas experiências teatrais. In: MATO, D. (ed.). Cultura, política y sociedad perspectivas latinoamericanas. Caracas: Consejo Latinoamericano de Ciencias Sociales, 2002, p. 265-276.

SARLO, B. Cultural studies questionnaire. Journal of Latin American cultural studies, v. 6, n. 1, p. 85-92, 1997. DOI: 10.1080/13569329709361901

Raymond Williams, una relectura. In: MORAÑA, M. (ed.) Nuevas perspectivas desdel sobre América Latina: el desafío de los Estudios Culturales. Santiago: Editorial Cuarto Propio and Instituto Internacional de Literatura Iberoamericana, 2000. p. 309-317. (Tradução da publicação: Raymond Williams, una relectura. Punto de Vista, n. 45: p. 13, abr. 1993).

SCHUTTE, O. Cultural identity and social liberation in Latin American thought. Albany: SUNY Press, 1993.

SOTO SULCA, R. (ed.). Discurso y poder en Stuart Hall. Huancayo, Perú: Imprenta Grafica MELGRAPHIC E.I.R.L., 2013.

SOVIK, L. (ed.). Apresentação para ler Stuart Hall. In: ___ Da diáspora: identidades e mediações culturais (uma coleção de artigos de Stuart Hall). Belo Horizonte; Brasília: UFMG; 2003a, p. 9-21.

(ed.). Da diáspora: identidades e mediações culturais (uma coleção de artigos de Stuart Hall). Belo Horizonte; Brasília: UFMG; 2003 b.

STUART HALL A PARTIR DO BRASIL. $23^{\circ}$ encontro anual da associação nacional dos programas de pós-graduação em comunicação... Pará, 27-30 maio 2014a.

. Os projetos culturais e seu significado social. Galáxia, v. 27, p. 172182, 2014b. DOI: http://dx.doi.org/10.1590/1982-25542014110411.

SUNKEL, G. El consumo cultural en la investigación en comunicaciones en América Latina. Contornos: signo y pensamiento, v. 12, n. 45, p. 9-24, 2004.

VALENCIA, I. H. Antropología y estudios culturales: entre el teorizar de la política y la politización de la teoría. Tabula Rasa, v. 15, p. 95-111, 2011.

VORRABER-COSTA, M.; WORTMANN, M. L. C.; SILVEIRA, R. M. H. Stuart Hall: tributo a um autor que revolucionou as discussões em educação no Brasil. Educação \& realidade, v. 39, n. 2, p. 635-649, 2014. DOI: http:// dx.doi.org/10.1590/S2175-62362014000200015 
WORTMANN, M. L.; COSTA, M. V.; SILVEIRA, R. M. H. Sobre a emergência e a expansão dos estudos culturais em educação no Brasil. Educação, v. 38, n. 1, p. 32-48, 2015. DOI: http://dx.doi.org/10.15448/19812582.2015.1.18441

Artigo recebido em 16 de setembro de 2015 e aprovado em 05 de novembro de 2015 . 
